\title{
Application of MSWI bottom ash as alternative aggregate in cement mortar
}

\author{
Z. Pavlík, M. Keppert, M. Pavlíková, P. Volfová \& R. Černý \\ Department of Materials Engineering and Chemistry, Faculty of Civil \\ Engineering, Czech Technical University in Prague, Czech Republic
}

\begin{abstract}
Bottom ash generated by municipal solid waste incinerators (MSWI) is used as partial replacement of silica aggregate in cement mortar. For comparative reasons, also reference cement mortar without ash addition is studied. At first, measurement of particle size distribution of studied bottom ash is done using laser particle size analyser and sieves of specific dimensions. Basic material properties of cement mortar, namely the bulk density, matrix density, and total open porosity, are measured using gravimetric method combined with helium pycnometry. Pore size distribution is determined by mercury porosimetry. Compressive strength and bending strength characterizing mechanical performance of the mortar and moisture diffusivity as a basic indicator of durability are analyzed as well. Experimental results show that the replacement of siliceous sand by bottom ash aggregates in an amount of up to $40 \%$ of mass leads to an increase in mechanical properties and slowing-down of water penetration into cement mortar. This is a very prospective outcome for the practical application of the mortar, particularly taking into account that the use of waste bottom ash in building materials production is beneficial from both economical and ecological points of view.
\end{abstract}

Keywords: municipal solid waste incineration, bottom ash, cement mortar, aggregate replacement, basic material properties, mechanical properties, durability.

\section{Introduction}

The continuous decrease of fossil fuels supplies, an increase in their prices and last but not least the impact of their consumption on the living environment is reflected in the operating expenses of buildings. Another serious problem 
represents an increase in building materials production. The building materials are manufactured mainly on natural basis, what has harmful effect on the living environment quality. For example, among all construction materials around $65 \%$ is concrete, produced in the world at an approximate rate of 4600 millions of $\mathrm{m}^{3}$ per year. However, in current construction technology not only the final advanced properties of materials should be considered. Also the energy- and natural materials consumption should be taken into account. Hence, the secondary raw materials find widespread use in building materials production.

At burning of municipal solid waste (MSW) in incinerators, mineral solids in form of fly ash and bottom ash are produced. The amount of produced fly ash is negligible and it is so chloride-rich that without complex treatment it cannot be used as mineral addition in cement-based mixtures, especially for reinforced concrete structures. On the other hand, the content of chlorides in bottom ash is negligible; thus it could be potentially used for manufacturing of concrete mixtures [1]. The ashes from MSWI can be basically applied in a similar way as fly ashes from power- and heating plants which technology and application in building materials, such as cement, concrete, artificial light aggregates, bricks and ceramics, is nowadays well established [2-5]. However, their chemical, mineralogical and granulometry composition and the possible toxicity remainders have to be taken into account.

In this paper, the use of bottom ash generated by municipal solid waste incinerators (MSWI) as partial replacement of silicate aggregates in cement mortar is studied, whereas its fine granulometry should optimise the grain-size curve of applied silica sand. One must take into account, the great advantage in the sustainability of concrete production which may be achieved, if the MSWI bottom ashes could be used hereat. In this way, the residues of municipal solid waste incineration, which are available in great quantities over the world, could be converted into a resource able to produce quality concrete.

\section{Studied materials}

Two types of cement mortars containing MSWI bottom ash as partial silica sand replacement denoted ZR 10, ZR 40 were analysed, together with the reference mortar ZR without MSWI bottom ash addition. The composition of studied materials is given in Table 1.

Table 1: Composition of researched materials.

\begin{tabular}{|c|c|c|c|c|}
\hline \multicolumn{2}{|c|}{} & ZR & ZR 10 & ZR 40 \\
\hline Portland cement CEM 42.5 R & $\mathrm{g}$ & 2000 & 2000 & 2000 \\
\hline Bottom ash & $\mathrm{g}$ & 0 & 600 & 2400 \\
\hline Silica sand 0/4 mm & $\mathrm{g}$ & 6000 & 5400 & 3600 \\
\hline Water & $\mathrm{ml}$ & 1040 & 1040 & 1040 \\
\hline
\end{tabular}

The applied bottom ash was produced by the MSWI Termizo Liberec, Czech Republic. Its chemical composition determined by X-ray fluorescence (XRF) analysis is presented in Table 2 . XRF is just a semi-quantitative technique; hence 
the results have to be taken into account just as indicative (an error as high as $20 \%$ may be estimated). We can see that the amount of chlorides is very low, what is beneficial from the point of view of possible reinforcement corrosion in case of application of studied materials in construction concrete.

Table 2: Chemical composition of applied bottom ash measured by XRF (in \%).

\begin{tabular}{|c|c|}
\hline $\mathrm{SiO}_{2}$ & 33.5 \\
\hline $\mathrm{Al}_{2} \mathrm{O}_{3}$ & 15.8 \\
\hline $\mathrm{Fe}_{2} \mathrm{O}_{3}$ & 8.4 \\
\hline $\mathrm{CaO}$ & 19.4 \\
\hline $\mathrm{MgO}$ & 2.0 \\
\hline $\mathrm{SO}_{3}$ & 9.3 \\
\hline $\mathrm{ZnO}$ & 0.8 \\
\hline $\mathrm{Na}_{2} \mathrm{O}$ & 3.6 \\
\hline $\mathrm{K}_{2} \mathrm{O}$ & 1.9 \\
\hline $\mathrm{TiO}_{2}$ & 1.5 \\
\hline $\mathrm{Cl}$ & 1.1 \\
\hline$\Sigma$ & 97.1 \\
\hline
\end{tabular}

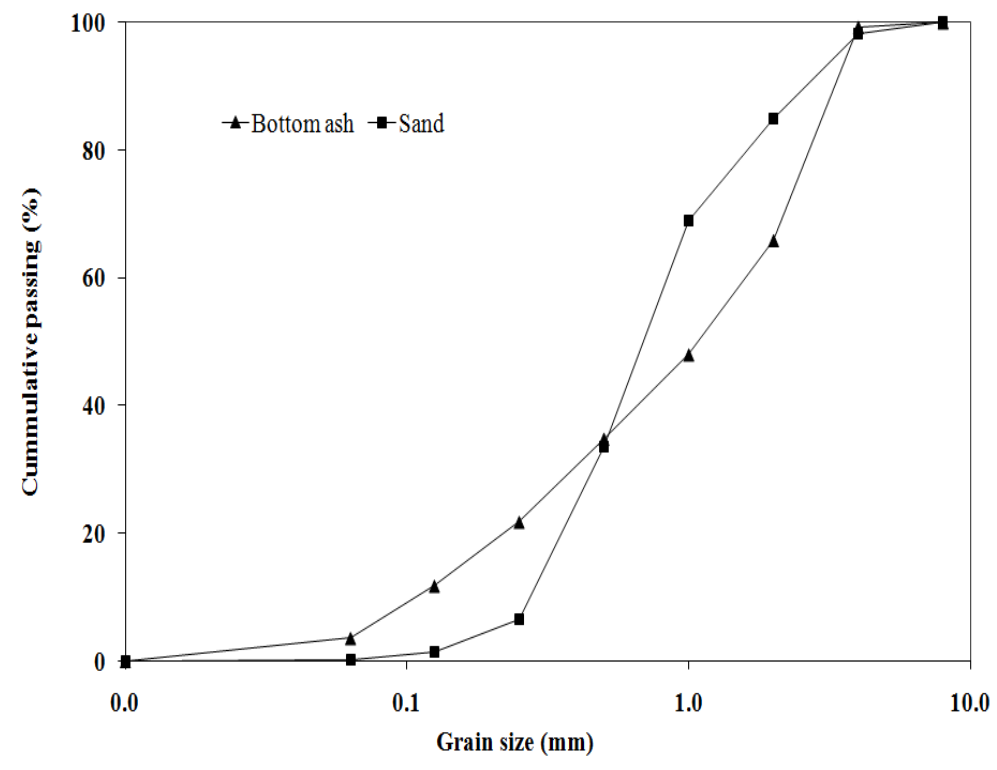

Figure 1: Grading curves of applied materials measured by sieves. 
The particle size distribution of the applied bottom ash and silica sand determined by standard grading analysis by set of sieves and laser particle size analyser Analysette 22 MicroTec plus are given in Figures 1 and 2. Since the laser analyser allows measurement of grain size up to $2 \mathrm{~mm}$, it was necessary to perform also the common sieving tests.

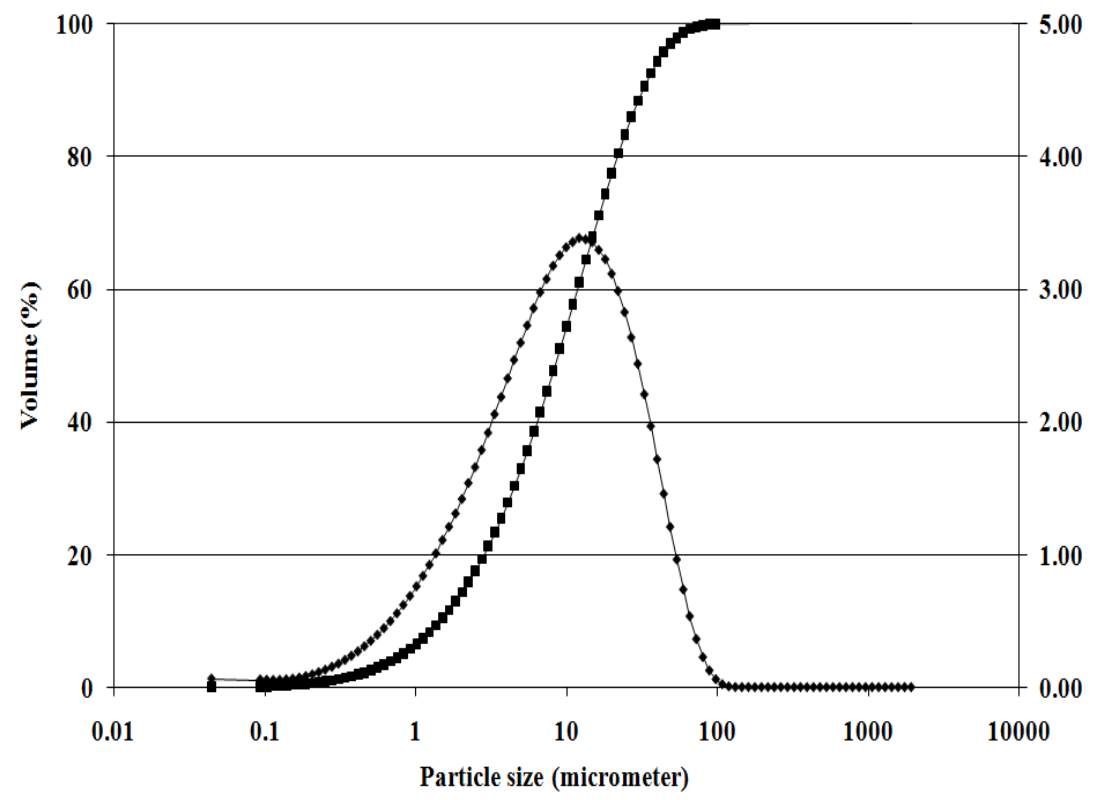

Figure 2: $\quad$ Particle size distribution of bottom ash measured by laser analyser.

\section{Experimental methods}

Basic material properties of all tested materials were determined at first. Bulk density and matrix density were measured using gravimetric method and helium pycnometry, and then total open porosity was calculated. For measurement of pore size distribution, mercury porosimeters Pascal 140 and Pascal 440 Thermo Scientific were used. Within the evaluation of measured data, the circular cross section of capillaries was assumed.

The bending strength was determined using the procedure described in ČSN EN 12390-5 [6], whereas the tests were performed after 28 days of standard curing. The compressive strength was measured according to the ČSN EN 12390-3 [7] on the portions of prisms broken in flexure; the loading area was 40 $\mathrm{x} 40 \mathrm{~mm}$.

For determination of moisture diffusivity as function of moisture content, the moisture profiles were measured at first. The measurements were done on samples having dimensions of $40 \times 20 \times 300 \mathrm{~mm}$ in 1-D experimental arrangement of water transport. On this account, all the lateral sides of the samples were water and water vapour proof insulated by epoxy resin. The 
moisture content in specific positions in a sample was measured by gravimetric method. The moisture dependent moisture diffusivity was then calculated using inverse analysis of measured moisture profiles by means of Boltzmann-Matano treatment [8].

\section{Results and discussion}

Basic material properties of researched materials are given in Table 3. We can see that the partial replacement of silica sand led to an increase of total open porosity.

Table 3: Basic physical properties of studied materials.

\begin{tabular}{|c|c|c|c|}
\hline & Matrix density $\left(\mathrm{kg} / \mathrm{m}^{3}\right)$ & Bulk density $\left(\mathrm{kg} / \mathrm{m}^{3}\right)$ & $\begin{array}{c}\text { Total open } \\
\text { porosity }(\%)\end{array}$ \\
\hline ZR & 2662 & 2105 & 20.9 \\
\hline ZR 10 & 2671 & 2013 & 24.6 \\
\hline ZR 40 & 2650 & 1911 & 27.9 \\
\hline
\end{tabular}

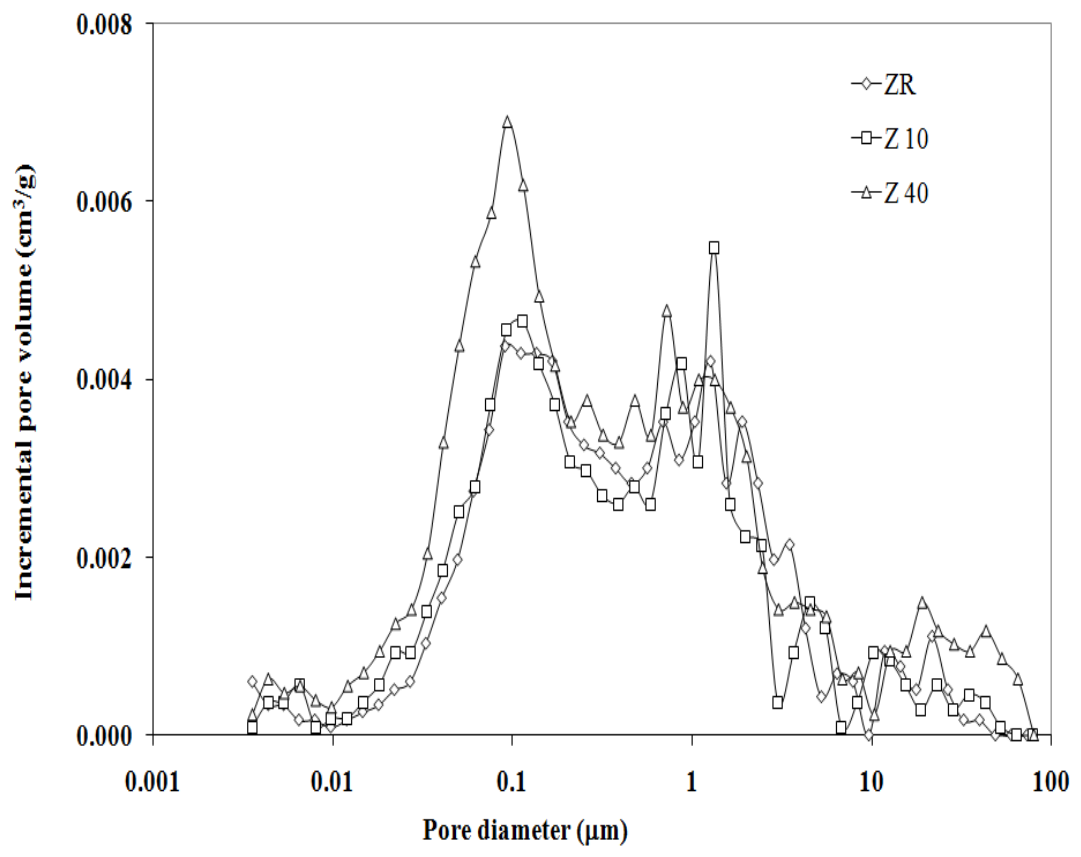

Figure 3: Pore size distribution of studied mortars.

The data of mercury porosimetry measurement, which are summarized in Figure 3, reveal a substantial increase in the volume of smaller pores of materials with MSWI bottom ash. The amount of larger pores remains basically 
unaffected. Therefore, the higher values of total open porosity shown in Table 3 may not represent a limiting factor for the practical application of studied materials containing MSWI bottom ash.

Results of mechanical properties measurement are presented in Table 4. Here, the addition of MSWI bottom ash contributes significantly to the mechanical performance of developed materials.

Table 4: $\quad$ Mechanical properties of studied materials.

\begin{tabular}{|c|c|c|}
\hline & Compressive strength (MPa) & Bending strength (MPa) \\
\hline ZR & 41.0 & 6.5 \\
\hline ZR 10 & 42.0 & 7.0 \\
\hline ZR 40 & 45.0 & 7.5 \\
\hline
\end{tabular}

The moisture profiles measured after 28 days of water penetration are presented in Figure 4. The moisture diffusivities calculated as functions of moisture content on the basis of inverse analysis of moisture profiles are shown in Figure 5. Apparently, water transport was significantly slower in the materials containing MSWI bottom ash, as compared with reference mortar. This finding indicates an important contribution of MSWI bottom ash to the durability of studied materials.

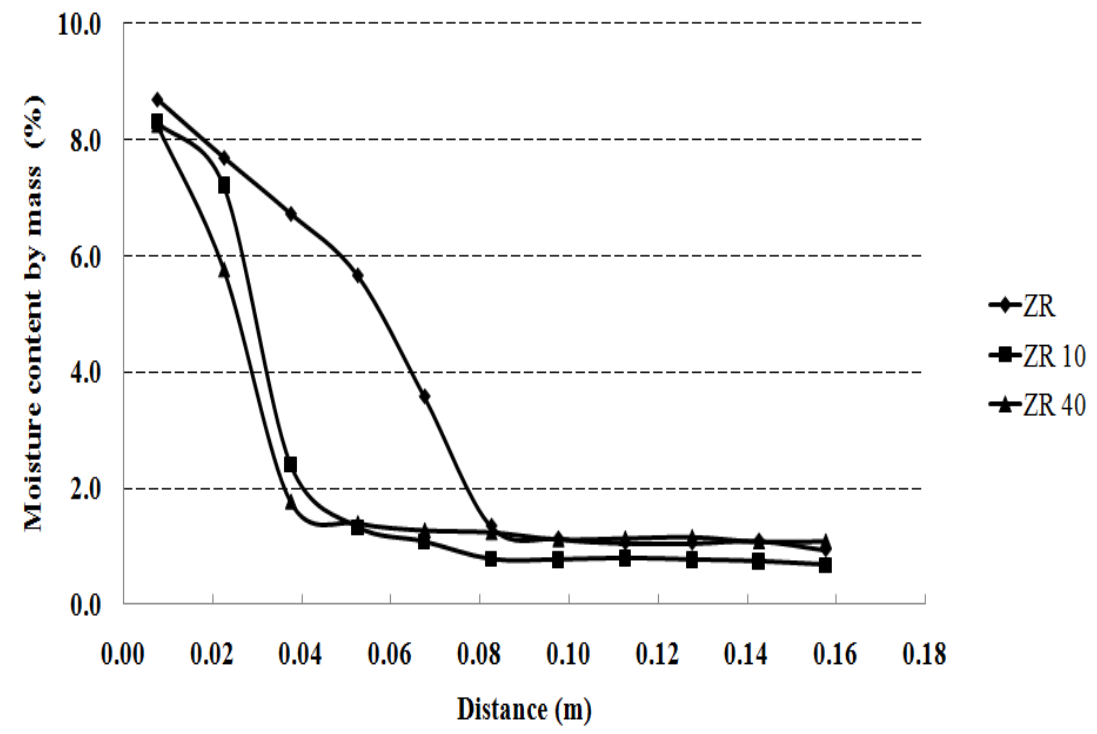

Figure 4: $\quad$ Moisture profiles measured for water penetration time of 28 days. 


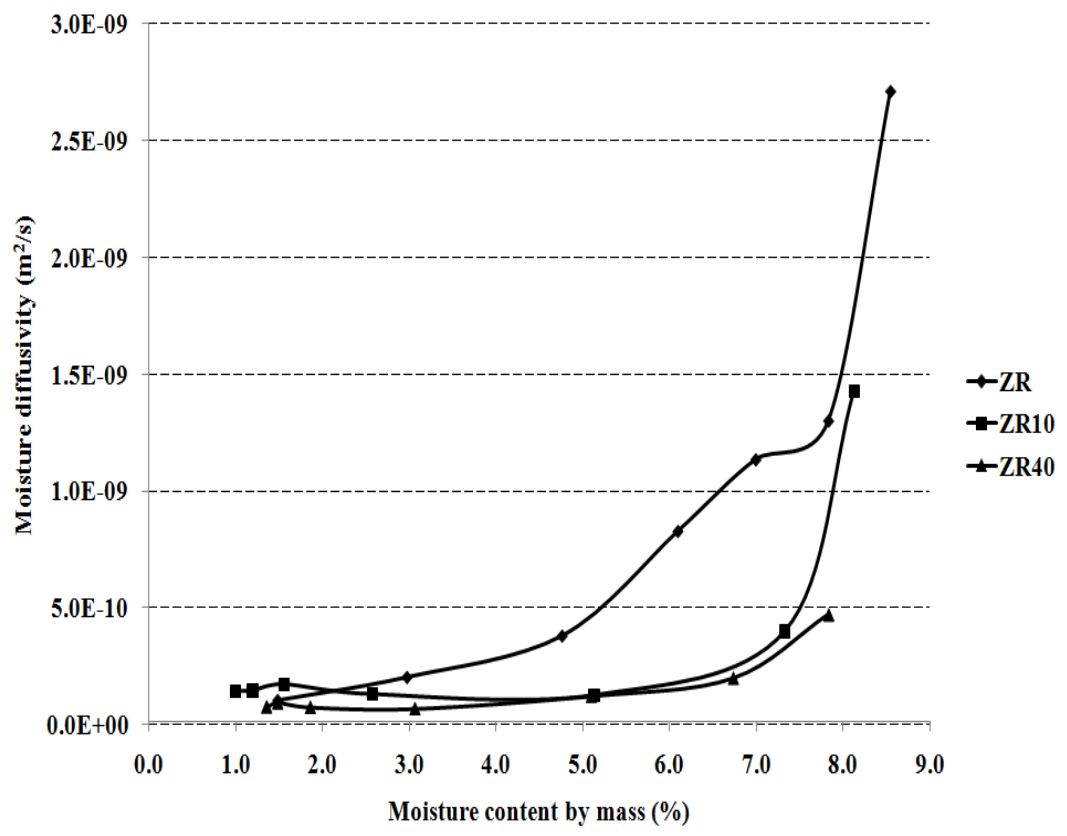

Figure 5: $\quad$ Moisture diffusivity of studied mortars.

\section{Conclusions}

Experimental results presented in this paper demonstrated a good potential for the application of MSWI bottom ash as partial replacement of silica sand in cement mortar. The use of MSWI bottom ash resulted in the improvement of mechanical properties of cement mortar. Also, water transport was slowed down, indicating higher durability of modified mortars in comparison with reference mortar without bottom ash addition. However, for a practical application of studied materials in building industry, some additional tests are still necessary to be done, for example the resistance against freeze/thaw cycles, de-icing salts, and drying/wetting cycles.

\section{Acknowledgement}

This research has been supported by the Czech Science Foundation, under project No. P104/11/0438.

\section{References}

[1] Collepardi, M., Collepardi, S., Ongaro, D., Curzio, A.Q. \& Sammartino, M., Concrete with Bottom Ash from Municipal Solid Wastes Incinerators. Proc. 
$2^{\text {nd }}$ International Conference on Sustainable Construction Materials and Technologies, Ancona, pp. 289-298, 2010.

[2] Bertolini, L., Carsana, M., Cassago, D., Quadrio Curzio, A., Collepardi, M., MSWI ashes as mineral additions in concrete. Cement and Concrete Research, 34, pp. 1899-1906, 2004.

[3] Kikuchi, R., Recycling of MSW for cement production: pilot-scale test for transforming incineration ash of solid waste into cement clinker. Resources, Conservation and Recycling, 31, pp. 137-147. 2001.

[4] Lin, K.L., Wang, K.S., Tzeng, B.Y., Lin, C.Y., The reuse of municipal solid waste incinerator fly ash slag as a cement substitute. Resources, Conservation and Recycling, 39, pp. 315-324, 2003.

[5] Keppert, M., Reiterman, P., Pavlík, Z., Pavlíková, M., Jerman, M., Černý, R., Municipal solid waste incineration ashes and their potential for partial replacement of Portland cement and fine aggregates in concrete. Cement Wapno Beton, 15/77(4), pp. 187-193, 2010.

[6] ČSN EN 12390-5, Testing of hardened concrete - Part 5: Bending strength, Czech Standardization Institute, Prague, 2007

[7] ČSN EN 12390-3, Testing of hardened concrete - Part 3: Compressive strength, Czech Standardization Institute, Prague, 2002.

[8] Roels, S., Carmeliet, J., Hens, H., Adan, O., Brocken, H., Černý, R., Pavlík, Z., Hall, C., Kumaran, K., Pel, L., A Comparison of Different Techniques to Quantify Moisture Content Profiles in Porous Building Materials. Journal of Thermal Envelope \& Building Science, 27(4), pp. 261-276, 2004. 